\title{
Processamento de sementes de Moringa oleifera utilizando-se diferentes equipamentos para obtenção de solução coagulante
}

\author{
Camila C. Arantes ${ }^{1}$, Tulio A. P. Ribeiro ${ }^{2}$ \& José E. S. Paterniani ${ }^{2}$
}

\begin{abstract}
RESUMO
Desenvolveu-se este trabalho para avaliar o uso de quatro equipamentos no processamento das sementes de Moringa oleifera, visando à produção de solução coagulante a ser empregada no tratamento de água com turbidez obtida sinteticamente. Seis soluções coagulantes com diferentes tipos de processamento foram utilizadas em ensaios de coagulação, floculação e sedimentação em equipamento Jar-Test. A dosagem da solução coagulante utilizada foi $500 \mathrm{mg} \mathrm{L}^{-1}$ e os parâmetros avaliados foram turbidez e cor aparente; verificou-se, após 30 min de sedimentação, que para redução de turbidez e cor aparente os melhores processamentos foram com pilão e máquina de moer, respectivamente, sendo que em ambos os casos o peneiramento do pó foi essencial para a redução dos parâmetros em questão. Através de liquidificador e mixer, os índices de redução de turbidez e cor aparente foram os menores encontrados e a trituração das sementes durante o processamento na máquina de moer e no pilão remove parte do óleo neles presente, o que não ocorre com o uso do liquidificador e mixer, evidenciando que a retirada do óleo presente nas sementes resulta em solução coagulante com maior eficiência.
\end{abstract}

Palavras-chave: tratamento de água, coagulantes naturais, extração de óleo, redução de turbidez, redução de cor aparente

\section{Processing of Moringa oleifera seeds using different equipments to obtain coagulant solution}

\begin{abstract}
This work was condcted to assess four different equipments used in processing seeds of Moringa oleifera to produce a coagulant solution to be used in water treatment with the turbidity obtained synthetically. Six coagulant solutions with different types of processing were used in assays of coagulation, flocculation and sedimentation in Jar-Test equipment. The dose of coagulant solution was $500 \mathrm{mg} \mathrm{L}^{-1}$ and the evaluated parameters were turbidity and apparent color. After 30 min of sedimentation, it was clear that the best processes to reduce turbidity and apparent color were the pestle and grinder, respectively, however, in both cases the sieving of the powder was essential in reducing the parameters in question. Using a blender and a mixer the reduction rates of turbidity and apparent color were the lowest. The grinding of the seeds during processing in the grinder and the pestle remove part of the oil present in them, which does not occur when using the blender and mixer, stating that the removal of oil present in the seeds result in a more efficient coagulant solution.
\end{abstract}

Key works: water treatment, natural coagulants, oil extraction, turbidity reduction, apparent color reduction 


\section{INTRODUÇÃO}

Quando coletada para uso doméstico, a água de mananciais superficiais pode conter impurezas, particularmente na estação chuvosa, pois a água carrega sedimentos, partículas em suspensão, dissolvidas e coloidais, além de micro-organismos e outros contaminantes passíveis de causar danos à saúde humana. Desta forma, quando destinada ao consumo humano é conveniente que se removam tais impurezas contidas na água o que é feito, normalmente, em estações de tratamento de água, utilizando-se coagulantes químicos.

Coagulantes são espécies químicas capazes de promover a desestabilização de partículas em processo denominado coagulação. Após a desestabilização das partículas ocorre a floculação, quando então as partículas desestabilizadas são submetidas a choques entre si, unindo-se umas às outras e formando flocos passíveis de remoção por sedimentação e/ou filtração (Di Bernardo \& Dantas, 2005; Libânio, 2008).

Amagloh \& Benang (2009) afirmam que o método convencional de tratamento de água utilizando coagulantes à base de sais de ferro ou alumínio, pode tornar o tratamento de água em países em desenvolvimento inviável, devido a necessidade desses países de importar tais produtos, muito caro e além do alcance de populações rurais. Para regiões menos favorecidas e com carência de sistemas de tratamento de água e saneamento, um dos tratamentos recomendados para melhoria da qualidade da água é o uso de coagulantes naturais, que podem ser obtidos de plantas, como a Moringa oleifera.

A Moringa oleifera é uma espécie vegetal da família Moringaceae, originária do nordeste indiano, amplamente distribuída na Índia, Egito, Filipinas, Ceilão, Tailândia, Malásia, Burma, Pasquitão, Singapura, Jamaica e Nigéria (Gallão et al., 2006) de fácil cultivo e adaptação no Brasil, principalmente no Nordeste. As sementes de tal planta são bastante utilizadas na clarificação de águas turvas em diversas regiões carentes do planeta, como no Sudão, outros países da África, no Nordeste brasileiro, entre outros (Borba, 2001).

Os estudos científicos iniciais relacionados ao uso desta planta como coagulante, foram desenvolvidos na Alemanha e na Inglaterra, na década de 80. O Grupo de Engenharia Ambiental da Universidade de Leicester, Inglaterra, tem estudado o uso potencial de coagulantes naturais em grande escala no tratamento de água, sendo realizados testes com as propriedades naturais de coagulação da semente de Moringa oleifera triturada.

Pesquisas efetuadas na década de 90 (Ndabigengesere et al., 1995; Okuda et al., 1999) demonstraram que proteínas com alto peso molecular presentes nas sementes de Moringa oleifera são responsáveis pelo processo de coagulação, cujas constatações são confirmadas em estudos mais recentes (Ghebremichael et al., 2005; Agrawal et al., 2007).

A obtenção de solução coagulante à base de sementes de Moringa oleifer, é reportada de diferentes maneiras na literatura não havendo, no entanto, padronização para tal procedimento. Há procedimentos manuais nos quais se utiliza pilão para trituração das sementes (Okuda et al., 1999; Okuda et al., 2001) podendo ocorrer, após trituração, peneiramento do pó obtido para retirada de partículas maiores (Paterniani et al., 2009; Paterniani et al., 2010). Outros autores adotam a metodologia com obtenção do pó utilizando liquidificador doméstico ou (Ndabigengesere et al., 1995; Katayon et al., 2006) e até mesmo preparo da solução diretamente no liquidificador (Madrona et al., 2010).

Neste contexto, o presente estudo teve por objetivo avaliar e comparar o uso de quatro equipamentos domésticos no processamento das sementes de Moringa oleifera para obtenção de solução coagulante a ser utilizada no tratamento de água para a redução de turbidez e cor aparente.

\section{MATERIAL E MÉTODOS}

Este trabalho foi desenvolvido no Laboratório de Saneamento da Faculdade de Engenharia Agrícola da Universidade Estadual de Campinas, com o uso de quatro tipos de equipamentos no processamento de sementes de Moringa oleifera com vista à obtenção de solução coagulante, para o tratamento de água.

No método adotado neste trabalho considerou-se importante avaliar e comparar a eficiência de equipamentos já adotados no processamento das sementes e propor o uso de outros equipamentos alternativos. O uso de sementes de Moringa oleifera por populações desprovidas de sistemas de tratamento de água para melhoria da sua qualidade, requer que os equipamentos utilizados para seu processamento sejam de fácil acesso e manuseio. Portanto, foram escolhidos os seguintes equipamentos para o processamento das sementes de Moringa oleifera: máquina de moer, pilão, liquidificador e mixer.

As sementes utilizadas neste trabalho foram colhidas no Campo Experimental da Faculdade de Engenharia Agrícola em períodos de estiagem, evitando que uma umidade maior, proveniente de chuva, pudesse deteriorar as sementes ou possibilitar a proliferação de micro-organismos, interferindo na qualidade das mesmas; após a colheita as sementes com casca permanecerão entre três e quatro dias em dessecador, para diminuição da umidade natural; em seguida, as sementes foram acondicionadas em garrafas PET e armazenadas a temperatura de aproximadamente $5{ }^{\circ} \mathrm{C}$; por fim, seguindo recomendações de Ndabigengesere \& Narasiah (1998) a solução coagulante era preparada sempre no momento da realização do ensaio.

Para obtenção do pó de Moringa oleifera através da máquina de moer, as sementes foram primeiro descascadas e moídas até que não restassem mais sementes no interior da máquina; depois, o volume coletado foi novamente moído por mais duas vezes, e só então a máquina foi desmontada e todo o resíduo presente em seu interior foi removido e finalmente adicionado ao volume já coletado. O novo volume foi novamente moído mais duas vezes, totalizando o total de 5 vezes, para que houvesse não apenas um aproveitamento maior das sementes mas, também, a padronização do seu processamento. Finalmente, o volume total processado foi dividido em duas partes, a primeira direcionada diretamente para o preparo da solução líquida e a segunda foi homogeneizada em peneira com abertura de $0,8 \mathrm{~mm}$, para retirada de partículas maiores. 
De início, as sementes descascadas foram trituradas manualmente em um pilão de madeira e o volume total obtido foi dividido em 2 partes, em que uma foi utilizada sem homogeneização do tamanho das partículas e a outra passou por peneira com abertura de $0,8 \mathrm{~mm}$, com vista à retirada de partículas maiores. Com o objetivo de diminuir a variação dos tamanhos das partículas que não foram peneiradas, atentouse para o fato de que a trituração sempre fosse efetuada pela mesma pessoa e que o tempo de trituração e movimentos efetuados fossem, na medida do possível, similares em todos os ensaios realizados.

Ao pó pesado em quantidade relativa à concentração (massa/ volume) adicionou-se água destilada e se promoveu a homogeneização durante 2 min, em agitador magnético. A concentração adotada para a solução foi $20000 \mathrm{mg} \mathrm{L}^{-1}$ sendo que, para cada $100 \mathrm{~mL}$ de água destilada, eram utilizados 200 miligramas de pó; após homogeneização da solução há recomendações para que a mesma seja filtrada em papel filtro, membranas ou tecidos (Okuda et al., 2001; Ndabigengesere \& Narasiah, 1998; Katayon et al., 2006). Para maior facilidade operacional adotou-se o peneiramento da solução em peneira com abertura de $0,125 \mathrm{~mm}$.

Visando a um procedimento mais simplificado e prático, optou-se pelo uso do liquidificador e mixer para obtenção da solução coagulante sem necessidade de preparo do pó. Para tanto, sementes descascadas e inteiras foram adicionadas à água destilada utilizando-se a concentração de 2\% (massa/ volume); após 1 min de processamento, a uma velocidade de $1500 \mathrm{rpm}$ nos respectivos equipamentos, a solução resultante foi também peneirada em peneira com abertura de 0,125 mm.

Na Figura 1 se apresentam, de forma esquemática, todas as etapas adotadas no processamento das sementes e no preparo da suspensão coagulante.

A água submetida ao tratamento com as soluções coagulantes obtidas consistia de água com níveis de turbidez obtidos sinteticamente para que se tivesse um controle mais rigoroso, desses níveis de turbidez. O preparo da água foi efetuado em equipamento Jar-Test. Para a obtenção de valores de turbidez inicial de aproximadamente 105 UNT adicionaramse, em cada jarro, 2 L de água destilada e $800 \mathrm{mg}$ de bentonita; em seguida, manteve-se agitação com gradiente de velocidade de aproximadamente $400 \mathrm{~s}^{-1}$ e por $30 \mathrm{~min}$; após a agitação a água foi condicionada em baldes e mantida em repouso durante $24 \mathrm{~h}$ sendo que se recolheu, ao término deste período, o sobrenadante, com cuidado para evitar que ocorresse ressuspensão da bentonita sedimentada.

Utilizaram-se seis soluções coagulantes com diferentes tipos de processamento, realizando-se ensaios de coagulação, floculação e sedimentação em reatores estáticos (Jar-Test), com a finalidade de avaliar a eficiência de remoção das soluções quanto à turbidez e à cor aparente. A dosagem da solução coagulante foi adotada de acordo com estudos realizados anteriormente, em que a melhor dosagem, à base de sementes de Moringa oleifera, foi $500 \mathrm{mg} \mathrm{L}^{-1}$ para a água obtida sinteticamente, com turbidez de 105 UNT.

Na coagulação adotou-se o gradiente de velocidade de 800 $\mathrm{s}^{-1}$ pelo tempo de $60 \mathrm{~s}$ e na floculação o gradiente adotado foi de $40 \mathrm{~s}^{-1}$ durante $10 \mathrm{~min}$. Os valores dos gradientes adotados

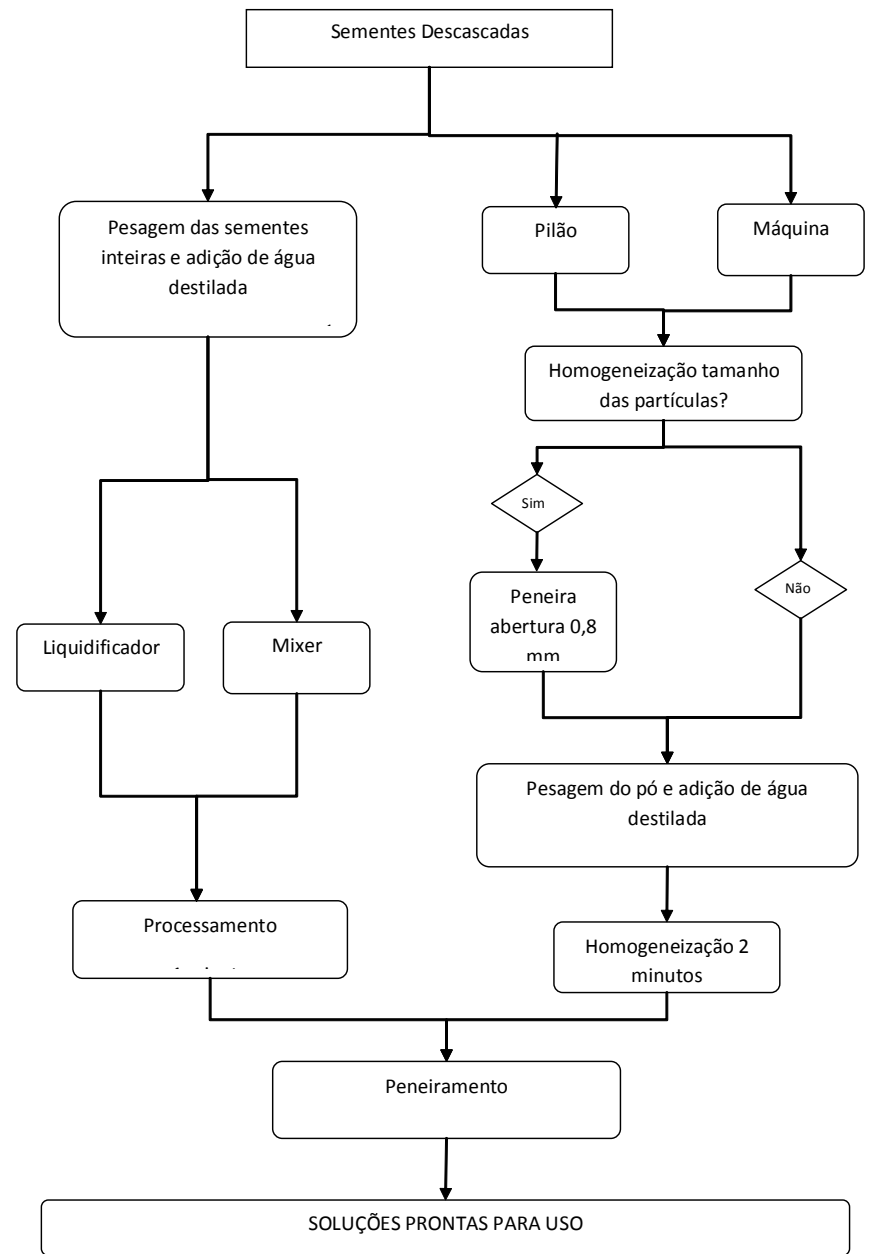

Figura 1. Fluxograma do processo de preparo da coagulante utilizando-se suspensão diferentes tipos de equipamentos

foram baseados em estudos anteriores; ao longo dos $30 \mathrm{~min}$ de sedimentação foram coletadas amostras em intervalos de 10 min entre as amostragens, tendo sido coletadas 4 amostras de cada jarro.

Nesta amostragem foram efetuadas 3 repetições para cada solução testada, totalizando-se 18 ensaios. Os parâmetros avaliados foram: turbidez e cor aparente. As análises foram realizadas com base no Standard Methods (APHA, 2005); por fim, a análise dos dados obtidos foi efetuada lançando-se mão da estatística descritiva, ou seja, média, desvio padrão e coeficiente de variação.

\section{RESULTADOS E DISCUSSÃO}

Em função do processamento adotado, utilizaram-se 6 soluções, denominadas da seguinte maneira: máquina de moer com pó peneirado (MP), máquina de moer com pó sem peneirar (MSP), pilão com pó peneirado (PP), pilão com pó sem peneirar (PSP), liquidificador (LIQ) e mixer (MIX).

$\mathrm{Na}$ Tabela 1 se encontram os valores de turbidez obtidos durante a etapa de sedimentação para os diferentes equipamentos utilizados no processamento das sementes de 
Tabela 1. Valores de turbidez obtidos durante sedimentação em função do equipamento utilizado

\begin{tabular}{|c|c|c|c|c|c|c|c|c|c|c|c|c|}
\hline \multirow{3}{*}{ Equipamento $^{3}$} & \multicolumn{12}{|c|}{ Turbidez (UNT) } \\
\hline & \multicolumn{3}{|c|}{$0 \mathrm{~min}$} & \multicolumn{3}{|c|}{$10 \mathrm{~min}$} & \multicolumn{3}{|c|}{$20 \mathrm{~min}$} & \multicolumn{3}{|c|}{$30 \mathrm{~min}$} \\
\hline & Média & $\mathrm{DP}^{1}$ & $\mathrm{CV}^{2}$ & Média & $\mathrm{DP}^{1}$ & $\mathrm{CV}^{2}$ & Média & $\mathrm{DP}^{1}$ & $\mathrm{CV}^{2}$ & Média & $\mathrm{DP}^{1}$ & $\mathrm{CV}^{2}$ \\
\hline MP & 168,33 & 6,11 & 3,63 & 3,69 & 0,41 & 11,22 & 2,71 & 0,33 & 12,23 & 2,18 & 0,32 & 14,49 \\
\hline MSP & 151,00 & 2,00 & 1,32 & 10,37 & 2,97 & 28,67 & 9,20 & 2,86 & 31,11 & 8,78 & 2,97 & 33,80 \\
\hline PP & 163,33 & 8,62 & 5,28 & 3,68 & 0,59 & 16,10 & 2,77 & 0,63 & 22,69 & 2,07 & 0,62 & 29,95 \\
\hline PSP & 144,67 & 6,43 & 4,44 & 15,97 & 2,19 & 13,74 & 14,60 & 2,12 & 14,50 & 14,33 & 2,20 & 15,37 \\
\hline LIQ & 173,67 & 8,39 & 4,83 & 26,87 & 9,21 & 34,28 & 24,67 & 7,74 & 31,37 & 23,93 & 7,16 & 29,92 \\
\hline MIX & 174,00 & 11,53 & 6,63 & 23,63 & 0,99 & 4,17 & 21,90 & 1,66 & 7,60 & 21,17 & 1,59 & 7,53 \\
\hline
\end{tabular}

${ }^{1}$ Desvio padrão

${ }^{2}$ Coeficiente de variação (\%)

${ }^{3}$ MP- máquina de moer peneirado; MSP - máquina de moer sem peneirar; PP - pilão peneirado; PSP - pilão sem peneirar; LIQ - liquidificador; MIX - mixer

Moringa oleifera com os respectivos valores de média, desvio padrão e coeficiente de variação.

De acordo com os valores mostrados na Tabela 1 foram observados, após 30 min de sedimentação, os menores valores de turbidez para a água tratada utilizando-se solução obtida a partir de sementes processadas no pilão e máquina de moer com peneiramento, com valores médios de turbidez na faixa de 2 UNT para as duas situações. Na utilização do pó sem peneiramento, os valores médios de turbidez no final da sedimentação, foram mais elevados, sendo que com utilização da máquina de moer o valor de turbidez apresentou-se inferior ao das sementes processadas no pilão, com valores médios de turbidez de 8,78 e 14,33 UNT, respectivamente, sinal de que, para uma boa eficiência de remoção da turbidez da água com a utilização de sementes de Moringa oleifera, o processo de peneiramento é muito importante. Quando se comparam os valores entre os processos com e sem peneiramento, com os equipamentos pilão e máquina de moer nota-se que, utilizandose o peneiramento, os valores são bem menores aos do sem peneiramento; por exemplo, caso se compare o valor de turbidez após $30 \mathrm{~min}$ para ambos os equipamentos com e sem peneiramento, a turbidez será 4 vezes menor com a máquina de moer com peneiramento e 6.9 vezes com o pilão.

Para o liquidificador, o valor médio de turbidez após sedimentação foi de 23,93 UNT, tendo ocorrido maior variação dos valores de turbidez durante o teste, em comparação com os outros equipamentos, quando os resultados mostraram valores do coeficiente de variação variando de 34,28 a 28,40. Com a utilização do mixer a turbidez média foi, após sedimentação, de 21,17 UNT, valor inferior ao obtido com o liquidificador. Comparando-se os seis tipos de processamento, o que apresentou maior redução de turbidez foi o pilão, com o pó peneirado; no entanto, não houve uma diferença tão considerável entre os dois equipamentos, o que pode ser justificado pelo fato de ambos os equipamentos processarem as sementes a uma mesma velocidade (1200 RPM).

Na Tabela 2 se relacionam os valores médios, desvios padrões e coeficientes de variação para o parâmetro cor aparente ao longo da sedimentação, com a utilização dos diferentes tipos de solução coagulante à base Moringa oleifera em função do modo de processamento das sementes.

Para redução de cor aparente, observou-se um comportamento próximo ao observado para a turbidez sendo que, para as sementes peneiradas, o valor médio de cor aparente após 30 min de sedimentação, foi menor no processamento com a máquina de moer em comparação ao pilão. Nota-se novamente que o processo de peneiramento é muito importante para a redução da cor aparente quando se utiliza o coagulante natural à base de semente de Moringa oleifera. Neste parâmetro, quando se comparam os valores com e sem peneiramento, a diferença entre eles é de 3,7 e 5 para os equipamentos máquina de moer e pilão respectivamente e, quando se compararam os dois equipamentos, a máquina de moer apresentou o melhor resultado, ou seja, o menor valor.

Com os valores entre os métodos de processamento mais práticos, ou seja, mixer e liquidificador, o melhor resultado foi encontrado com o uso do mixer; a diferença das médias entre eles em relação ao mixer, foi de $15,79 \%$ menor; para o parâmetro cor aparente, o melhor resultado de remoção de cor aparente foi com a máquina de moer com pó peneirado.

A Figura 2 ilustra a remoção média de turbidez e cor aparente após 30 min de sedimentação da água tratada. Foram utilizados os valores médios de turbidez e cor aparente da água bruta e após o período de sedimentação foram efetuados 3 ensaios

Tabela 2. Valores de cor aparente durante sedimentação em função do equipamento utilizado

\begin{tabular}{|c|c|c|c|c|c|c|c|c|c|c|c|c|}
\hline \multirow{3}{*}{ Equipamento $^{3}$} & \multicolumn{12}{|c|}{ Cor aparente $\left(\mathrm{mg} \mathrm{PtCo} \mathrm{L}^{-1}\right)$} \\
\hline & \multicolumn{3}{|c|}{$0 \mathrm{~min}$} & \multicolumn{3}{|c|}{$10 \mathrm{~min}$} & \multicolumn{3}{|c|}{$20 \mathrm{~min}$} & \multicolumn{3}{|c|}{$30 \mathrm{~min}$} \\
\hline & Média & $\mathrm{DP}^{1}$ & $\mathrm{CV}^{2}$ & Média & $\mathrm{DP}^{1}$ & $\mathrm{CV}^{2}$ & Média & $\mathrm{DP}^{1}$ & $\mathbf{C V}^{2}$ & Média & $\mathrm{DP}^{1}$ & $\mathbf{C V}^{2}$ \\
\hline MP & 865,00 & 43,59 & 5,04 & 18,00 & 4,00 & 22,22 & 14,33 & 3,06 & 21,31 & 11,00 & 2,65 & 24,05 \\
\hline MSP & 788,33 & 32,53 & 4,18 & 47,00 & 13,00 & 27,66 & 43,00 & 13,00 & 30,23 & 41,00 & 11,27 & 27,49 \\
\hline PP & 886,67 & 59,23 & 6,68 & 19,33 & 4,93 & 25,51 & 15,33 & 4,93 & 32,17 & 13,00 & 5,20 & 39,97 \\
\hline PSP & 746,67 & 33,29 & 4,46 & 73,00 & 10,15 & 13,90 & 66,67 & 10,21 & 15,32 & 66,00 & 11,27 & 17,07 \\
\hline LIQ & 921,67 & 120,66 & 13,09 & 128,33 & 43,88 & 34,19 & 114,67 & 36,69 & 32,00 & 110,00 & 31,24 & 28,40 \\
\hline MIX & 998,33 & 81,29 & 8,14 & 111,00 & 3,61 & 3,25 & 100,33 & 9,07 & 9,04 & 95,00 & 6,93 & 7,29 \\
\hline
\end{tabular}

1 Desvio Padrão

${ }^{2}$ Coeficiente de variação (\%)

${ }^{3}$ MP- máquina peneirado; MSP - máquina sem peneirar; PP - pilão peneirado; PSP - pilão sem peneirar; LIQ - liquidificador; MIX - mixer 
para obtenção da eficiência de redução de turbidez e cor aparente.

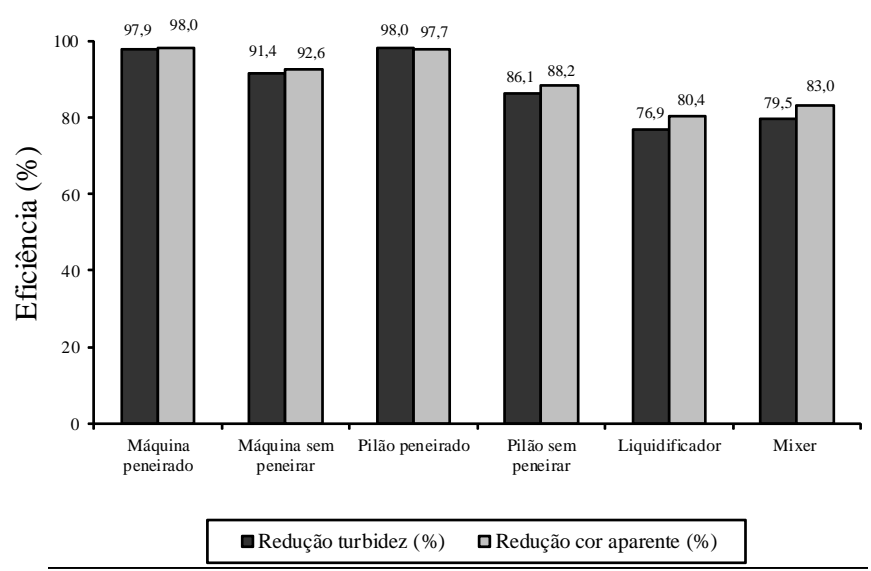

Figura 2. Remoção média de turbidez e cor aparente, após 30 min de sedimentação

A eficiência de redução de turbidez e cor aparente se mantiveram próximas para o processamento, em um mesmo equipamento. Este fato ocorreu porque os dois parâmetros de qualidade de água estão relacionados com a concentração de sólidos presentes na água. Com exceção do processamento no pilão com peneiramento, a redução de turbidez foi ligeiramente superior à redução de cor aparente, tendo-se observado uma diferença mais acentuada para o processamento no liquidificador e no mixer. Nota-se que o processo de peneiramento é essencial para uma eficiência maior de remoção, para ambos os parâmetros analisados

Para o processamento das sementes utilizando-se o liquidificador e mixer, os índices de redução de tais parâmetros foram os menores encontrados, com o liquidificador tendo apresentado os menores resultados de remoção.

Deve-se considerar que, quando o processamento foi efetuado no pilão e na máquina de moer com a trituração das sementes, houve remoção de parte do óleo presente nas sementes que ficou aderido ao equipamento utilizado no processamento; já com a utilização do liquidificador e mixer, as sementes eram processadas diretamente em meio líquido não ocorrendo, portanto, remoção de óleo. Silva \& Matos (2008) verificaram, comparando sementes com óleo e sementes sem óleo, que a solução obtida a partir de sementes sem óleo apresentou maior redução de turbidez e cor aparente. Para esses autores, a extração do conteúdo oléico permite uma sedimentação melhor de sólidos após a coagulação-floculação, o que corrobora com os dados obtidos nesta pesquisa.

\section{ConclusõEs}

1. Soluções preparadas a partir do processamento das sementes na máquina de moer e pilão com pó peneirado foram mais eficientes na redução de turbidez e cor aparente.

2. O processamento na máquina de moer e no pilão contribuiu para a retirada de parte do óleo presente nas sementes, o que resultou em solução coagulante com maior eficiência se comparado com o processamento no liquidificador e mixer.

\section{AgradeCIMENTOS}

Os autores agradecem à FAPESP (Processo: 2008/53066-0) e ao CNPq (Processo: 551388/2007-2) pelo financiamento da pesquisa e a CAPES pela bolsa de mestrado concedida à autora.

\section{LITERATURA CITADA}

Agrawal, H.; Shee, C.; Sharma, A. K. Isolation of a 66 KDa protein with coagulation activity from seeds of Moringa oleifera. Global Journal of Biotechnology \& Biochemistry. v.2, p.36-39, 2007.

Amagloh, F. K.; Benang, A. Effectiveness of Moringa oleifera seed as coagulant for water purification. African Journal of Agricultural Research, v.4, p.119-123, 2009.

APHA - American Public Health Association. Standard Methods for the examination of Water and Wastewater. 21 ed. New York: APHA, 2005.

Borba, L. R. Viabilidade do uso da Moringa oleifera lam no tratamento simplificado de água para pequenas comunidades. João Pessoa: UFPB, 2001. 96p. Dissertação Mestrado

Di Bernardo, L.; Dantas, A. D. B. Métodos e técnicas de tratamento de água. 2.ed. São Carlos: RiMa, 2005. 792p.

Gallão, M. I.; Damasceno, L. F.; Brito, E. S. Avaliação química e estrutural da semente de Moringa. Revista Ciência Agronômica, v.37, p.106-109, 2006.

Ghebremichael, K. A., Gunaratn, K.R., Henriksson, H., Brumer, H., Dalhamman, G. A simple purification and activity assay of the coagulant protein from Moringa oleifera seed. Water Research, v.39, p.2338-2344, 2005.

Katayon, S.; Noor, M. J. M. M.; Asma, M; Ghani, L. A. A.; Thamer, A. M.; Azni, I.; Ahmad, J.; Khor, B. C.; Suleyman, A. M. Effects of storage conditions of Moringa oleifera seeds on its performace in coagulation. Bioresource Technology, v.97, p.1455-1460, 2006.

Libânio, M. Fundamentos de qualidade e tratamento de água. 2.ed. Campinas: Editora Átomo, 2008. 444p.

Madrona, G. S.; Serpelloni, G. B.; Vieira, A. M. S.; Cardoso, K. C.; Bergamasco, R. Study of the effect saline solution on the extraction of the Moringa oleifera seed's active component for water treatment. Water Air Soil Pollution, v.211, p.409-415, 2010.

Ndabigengesere, A.; Narasiah, K.S. Quality of water treated by coagulation using Moringa oleifera seeds. Water Research, v.32, p.781-791, 1998.

Ndabigengesere, A.; Narasiah, K. S.; Talbot, B. G. Active agents and mechanism of coagulation of turbid waters using Moringa oleifera. Water Research, v.29, p.703-710, 1995.

Okuda, T.; Baes, A. U.; Nishijima, W.; Okada, M. Improvement of extraction method of coagulation active components from Moringa oleifera seed. Water Research, v.33, p.3373-3378, 1999. 
Okuda, T.; Baes, A. U.; Nishijima, W.; Okada, M. Isolation and characterization of coagulant extracted from Moringa oleifera seed by salt solution. Water Research, v.35, p.405-410, 2001.

Paterniani, J. E. S.; Mantovani, M. C.; Sant' Anna, M. R. Uso de sementes de Moringa oleifera para tratamento de águas superficiais. Revista Brasileira de Engenharia Agrícola e Ambiental, v.13, p.765-771, 2009.
Paterniani, J. E. S.; Ribeiro, T. A. P.; Mantovani, M. C.; Sant'Anna, M. R. Water treatment by sedimentation and slow fabric filtration using Moringa oleifera seeds. African Journal of Agricultural Research, v.5, p.1256-1263, 2010.

Silva, F. J. A.; Mattos, J. E. X. Sobre dispersões de moringa oleifera para tratamento de água. Revista de Tecnologia, v.29, p.157-163, 2008. 